\title{
A REFLECTION ON QUEERCRIP CHILD AND YOUTH CARE PRACTICE: DREAMS OF CARE AND FUTURITY
}

\section{Casper Gemar}

\begin{abstract}
This paper engages with a reflection on the author's embodied queercrip youth care praxis. The author uses queercrip theory to examine child and youth care practices and the relationships they hold to structures of power and domination. In so doing, he uses the terms eliminatory logics, survival dreaming, and crip constellations to understand the dynamics that undergird care and liberatory futures. Exploration of the (re)emerging queercrip paradigms that are the foundation of this work finds that these practices of care require moving beyond current imaginaries in youth care spaces. The paper concludes with recommendations for practice.
\end{abstract}

Keywords: queer, transgender, disabled, queercrip, futurity, dreaming, prefiguration

Casper Gemar (he/him/his) is a White queer and trans disabled youth care worker, educator, and community organizer. Casper is located on the occupied territories of the Lhaq'temish and Nooksack people- in the Pacific Northwest of the United States. Email: gemarc@wwu.edu 
This reflection is a love letter. To those who have taught me what it means to love with every reach of your body and soul. To those who move through life at a pace that is incongruent with abled society. To those who have found celebration and joy and desire and heart and future in the spaces and bodyminds ${ }^{1}$ they have been told are broken, who have made being broken fierce and exhilarating. This is a paper full of the knowledges that a middle-school-aged me felt hollow without. This is a thank you to those who have taught me how to laugh in my whole humanity amidst days, weeks, and years that felt impossible. This is only the beginning of my lifetime spent writing love letters to you.

As a young, queercrip ${ }^{2}$ youth worker, educator, and undergraduate student, I hope that, if nothing else, I can share with you some of the ways I have learned to love and care for myself and the youth I construct space with. It was in the journals that I keep on these practices that I first wrote about how my body was my first teacher in learning how to trust. I started a line of questioning in those journals: If I didn't know how to trust my own bodymind, my own feelings, my own flesh and bones and experience, how could I theorize from it? ${ }^{3}$ How could I trace the ways I have come to know what parts of the world hurt? And why? What structures and systems enforce the hurt, and how? And, most critically, what builds power against them? What understandings of our flesh and experience must we centre and learn from to build spaces where we (as educators, as students, as youth) feel whole enough to dream beyond the constructions of such spaces as schools and other care facilities? To build against those spaces that, at the end of the day, seek to ensure the continued existence of a state and society that seeks to erase us?

In this paper, I will explore these conversations and spaces of practice, writing to think about: (a) In what ways do I use the embodied knowledge of my trans, queer, and disabled self to push against the normative practices of child and youth care spaces? (b) In what ways are queercrip paradigms necessary for liberatory child and youth care spaces?

\section{Queercrip Locality}

Queercrip existence is fundamentally collaborative, responsive, non-hierarchical, connective, iterative, and expansive. In other words, a queercrip locality exists in a space and imagination

\footnotetext{
1"Bodymind" is a term that recognizes that our minds and bodies are deeply entangled and interconnected, rather than two entities that can be separated from each other. This term intentionally resists the harm of a mind/body split that is upheld by the norms of White, colonial culture. There are many variations of this term, including "bodymind" (Clare, 2017) and "body/mind" (Piepzna-Samarasinha, 2018).

${ }^{2 " Q u e e r c r i p " ~ i s ~ a ~ t e r m ~ t h a t ~ c o m b i n e s ~ " q u e e r " ~ a n d ~ t h e ~ r e c l a m a t i o n ~ o f ~ t h e ~ t e r m ~ " c r i p p l e " ~ t o ~ l o c a t e ~ a n d ~ b u i l d ~ p o w e r ~}$ within an identity and a bodymind that occupies both queer and disabled spaces. This is sometimes written "queercrip" or "queer crip". For further reading see Strauss (2018).

${ }^{3}$ This turn-of-phrase references the concept of "theory in the flesh" that was developed in the field of Chicana Feminism by Moraga and Anzaldúa (1983).
} 
beyond what is supposed correct and possible by White Western colonial thought. A queercrip locality highlights the intersectionality (Crenshaw, 1989) of multiple forms of oppression (or power relations). That is, histories of White supremacy, gender, and ableism are inextricable from the violence of colonialism, conquest, and capitalism (Sins Invalid, 2017). As such, the deconstruction of ableism and cisheteropatriarchy also necessitates the deconstruction of all entwined systems of control and domination - an affirmation of the understanding that our movements must be intersectional and our liberation must be collective.

It should be understood that a queercrip locality is one that cannot exist outside a movement for collective liberation grounded in the lineages, legacies, knowledges, movements, and traditions of Black, Brown, and Indigenous communities. It is critical to seek a disruption of the tendency that centres White stories and assumes them to be the default (or most valid) experience. This paper should not be read in isolation or assumed to be the default and only queercrip experience. This paper should be understood within a whole body of queercrip literature, much of which is written by Black, Indigenous, and other authors of color. Writing this paper as a White author who is queercrip requires that I navigate my positionality and privilege with great care and nuance. In line with the intersectional foundations of a queercrip locality, I work to understand how my identities as a White, trans, queer, disabled, and neurodivergent person shape how I experience and challenge power. Through these understandings, I also work to deconstruct the actions, thoughts, and socializations I have that are constructions of White-supremacy and colonialism. This paper is not going to be a perfect entrance into conversation, but will be part of a lifelong commitment to learn and work towards collective liberation and remain accountable to roots, people, and communities while working towards such a future.

In grounding my understandings of a queercrip locality for practice, I draw on Freeman's (2007) imagination of queer studies as:

A set of possibilities produced out of temporal and historical difference ... shaped by and reshaping not only various disciplines but also the studies of race, nation, migration, and postcolony ... this queer studies meets critical race theory and postcolonial studies in its understanding that what has not entered the historical records, and what is not yet culturally legible, is often encountered in embodied, nonrational forms: as ghosts, scars, gods. (p. 159)

Through this framing, I begin to trace the contours of a queercrip locality where an expanding set of possibilities emerges from the "queering" and "cripping" of space. This queercripping of space does not only encompass Ball's (2016) understanding that "queering something involves a deconstructive disposition that points to norms, resists them, and opens up space in which things might be done differently" (p. 35). It also pulls heavily from the embodied nature of the language used in asking: How do we lean the entire weight of our existence on a system until it breaks open enough to build in the cracks? (brown and Reagon, 2020, 50:30). The queercripping of space I seek to trace wonders if, perhaps, it could be the weight of our ghosts, scars, and gods - that is, 
our embodied knowledge - that enables us to break open the spaces that cannot hold us, and to build differently in their cracks.

Freeman (2007) named queerness as "not yet culturally legible" (p. 159), and I would argue that the nearly 15 years since she wrote this have suggested that perhaps queerness is fundamentally illegible to the logics of a White, Western, settler-colonial, cisheteropatriarchal, capitalist society. In the wake of landmark events such as the Obergefell v. Hodges (2015) U.S. Supreme Court case that legalized gay marriage, it has become clearer that the widespread legalization of gay marriage functions primarily as an assimilatory avenue for individuals to engage in heterosexual roles and restrictions and recieve some degree of acceptance for doing so (Conrad, 2014). Granting legal rights and protections to all queer ways of relating and being in partnerships, rather than just the ones that mimic straight capitalist society, would require that the logics of cisheteronormativity, capitalism, and settler colonialism could continue to operate while allowing for opposing ways of being to exist. I argue that because those logics are fundamentally eliminatory and rely on straight constructions of relationality in order to maintain order, queerness can never be fully legible to them.

Freeman's work is neither the first nor the last exploration of the cultural legibility in the relationship between queer identification and the cultural identification of queerness. In Muñoz's (2006) exploration of minoritarian affect, he examined how social logics projected onto the minoritarian subject results in minoritarian affect being, always, "partially illegible in relation to the normative affect performed by normative citizen subjects" (pp. 678-679). The concept of having your embodiment be illegible, or incomprehensible, as viewed through normative logics is also present when Piepzna-Samarasinha (2018) indicates to the reader some of the ways in which their book and their crip stories are beyond the stories about disability that can be comprehended by racist, ableist constructions of disability (p. 25). They also note this in their statement that "crip bodies and minds are too wild to fit" into traditional movements and nonprofit industrial complex structures (p. 124). The writing of Wilchins (2007) in Queer Theory, Gender Theory unites the work of Muñoz (2006) and Piepzna-Samarasinha (2018)into an understanding of how the phenomenon of being incomprehensible is (re)produced and maintained through a dominant societal narrative. In her discussion of Michel Foucault's work in regard to discursive power, Wilchins highlights the understanding that social truths about gender constructed through the dominant discourse of society create a narrative that portrays some bodies and minds as real and normal and, by exclusion, others as nonsensical. By extension, not only will embodied knowledges of the latter bodyminds always be seen to exist outside normative constructions of truth and reason, but, as long as constructions of their bodyminds are written within those dominant discourses that serve as a foundation for knowledge in normative spaces, they will remain objects of discourse rather than participants in discourse (Wilchins, 2007, pp. 60-61).

This is recognized in the popular knowledge of queercrip communities through the understanding that our bodies can never not exist in space - we cannot leave them at the door. Bodyminds deemed normal by the social truths professed in dominant discourse — by measures 
of ability, size, presentation, Whiteness, etc. - have the privilege of disappearing in spaces or passing through them. They have the privilege of writing themselves, to be read in the ways they desire. Queercrip bodyminds, and those of many other subaltern groups, are already written upon before they enter a room. Narratives constructed for us about who we are, can, and should be are always superimposed over our bodies, our stories, and our minds. We become one-dimensional to those viewing us through these logics. Who we really are, our substance and joy and love and fire and skills and humanity, is discarded - eliminated within the bounds and constructions of such discourse.

A queercrip locality, in its orientation towards liberatory futures, requires that we name the ways the dominant structures operate. I use the term "eliminatory logics" here and throughout this paper, drawing on Lytle Hernández's (2017) use of this term in describing how the foundational eliminatory logic of settler-colonialism structures the world for everyone in a settler society. She illustrates how this logic, deployed in many different ways, ultimately seeks "elimination in the service of establishing, defending, and reproducing a settler society" (p. 9). It is this understanding that underpins my use of "eliminatory logics" to describe the ways that oppressive structures settler-colonialism, White supremacy, anti-Blackness, cisheteropatriarchy, ableism, racial capitalism, etc. - function in daily life to support and reproduce each other through the elimination of other ways of knowing and being, such as queercrip ones.

Eliminatory logics can readily be found in mass media. For example, in the movie Million Dollar Baby (Eastwood, 2004), the newly disabled protagonist begs to die and is subsequently murdered. The trope perpetuated in this movie and in other media is that disabled people would be "better off dead than disabled". This eliminatory attitude, greatly compounded across intersections of identity, is manifested in the medical care disabled people receive (Asch, 2005). Another example can be found in conversion camps, which are based in the eliminatory view that queer and trans people need to be "cured" regardless of any harm and trauma inflicted in the process.

In choosing the term "eliminatory logics" for this paper, I aim to have it be an explicit and intentional reminder that spaces constructed within the context of dominant discourse are inextricably linked to the history, intentions, and functions of settler-colonialism, White supremacy, anti-Blackness, cisheteropatriarchy, ableism, and racial capitalism ${ }^{4}$ — to the elimination of all ways of being and knowing that do not reproduce and maintain their power and construction of normality. These structures don't only eliminate - they also punish, subjugate, control, restrict, and criminalize. However, within the context of this paper and within the context of a queercrip locality, it is my intention to be in conversation with the specific ways in which these systems set out to eliminate conceptions of queercrip embodiment by eliminating any fundamentally queercrip way of interacting with the world and others.

\footnotetext{
${ }^{4}$ Racial capitalism is "the process of deriving social and economic value from the racial identity of another person" (Leong, 2013, p. 2152).
} 
I include these framings with a goal of dismantling eliminatory logics and moving beyond their bounds: I don't include them to seek inclusion or legibility within eliminatory logics, as being legible to eliminatory logics would only serve to help perpetuate the system that seeks to eliminate the other. As Piepzna-Samarasinha (2018) noted, "The state was built on racist, colonialist ableism and will not save us, because it was created to kill us" (p. 23). History shows that as White liberal queers gained in state recognition, the Black and Brown liberatory origins of the queer movement in the United States were obscured and erased (Conrad, 2014), with the White queer positionality inadvertently being used to support the eliminatory projects of colonialism, imperialism, and antiBlackness (Briggs, 2012). Instead, challenging the logics of elimination requires that we continue to implicate settler-colonialism, anti-Blackness, White supremacy, capitalism, and the actions and structures that support them. This includes troubling the fact that we are all drawn into the reproduction of these structures through the prevalence of eliminatory logics in our lives.

In the liberatory project that rests in a queercrip locality and practice it is imperative to name the dominant structures and how they operate, but it is in the work to move beyond them to where our homes and futures rest. The imaginations for our homes and futures become possible in spaces informed by our embodied knowledges for the very reason that such knowledges are culturally illegible and outside the historical record. In the quotation above, Freeman (2007) listed embodied knowledges as often being encountered as ghosts, scars, and gods; I do not find the inclusion of our ghosts, scars, and gods to be separate from queercrip youth care practice. I have found that any practice capable of seeing and honouring the wholeness of those who occupy the margins cannot exist in isolation from our bodies, our homes, our relationships, or our histories. It cannot exist in the absence of what we know viscerally, even - and especially — if those knowledges are not culturally legible. There is a myth that prevails in many professional spaces, including schools and care facilities, that there is a necessity to leave everything at the door: to only enter with your mind and whatever disembodied knowledge has been deemed worthy. For those of us whose most important teachers have been our relationships with body, time, land, community, and rhythm, what is there left of us to enter the room with when our most significant knowledges have been deemed disposable? In the liminality of my ghosts, scars, and gods, I both return home and build my practice. It is through their languages that I understand myself. In my writings on ghosts, scars, and gods, I make sense of how I walk in this world.

As part of my journey as a youth worker dedicated to challenging eliminatory logics, I journal about my reflections, dreams, and thoughts for practice. My journals document my relationships with eliminatory logics and explore the power of my embodiment in challenging them. Below, I share a piece I wrote some months ago. It stands out for me in its exploration of scars as a medium to engage with corporeal understandings of memory, self, and the dispossessed feeling of a younger self. The outgrowth of this piece in my practice is a foundational understanding of how eliminatory spaces can leave scars, and, from that, one possible way to navigate the complex and 
nonlinear journey of healing ${ }^{5}$. I will share this piece with you so you can see these connections and the personal nature of some of my reflections. I hope the result of sharing this is a deeper understanding of how practices that are typically separated into the eliminatory binary of "personal" and "professional" are entangled. I do not hold the knowledges of my bodymind and the histories that have built them as a side note or addendum to disembodied strategies for practice. Rather, I place them at the core of my work.

It is okay that I do not have an uncomplicated relationship with my scars, my histories, my compulsions ... I will never know how many scars are on my body. Some have faded enough that I have to search for them, only sometimes uncovering their form on a sunny day at just the right angle. Some I will always see, always run my fingertips over, some feel lost to me. How is it that those moments of such pain are ghosts on my skin now? I still see my scars. I still marvel at the way they blanket my body. I still twist in the light to find paths my fingers can run along, feeling ghosts bubble up to lay across my thighs. And I still know there are so many so faded I may never hear their stories again or feel their fire rushing under the surface and maybe forgetting them is like the amnesia I used to wish for to forget the hurt ... but this time I just wish I could remember better the child that wore them. I will let the scars be part of me, remember for me, helping me honor the kid that got me here and grieve all he never should have gone through.

\section{Practitioner Context}

My practitioner context is primarily, and perhaps most significantly, in a middle-grades afterschool program in the Pacific Northwest of the United States that serves children aged 11 to 14. This context necessarily informs and is informed by community organizing work that recognizes that the practice of liberatory education is inextricable from that of collective struggle. ${ }^{6}$ While I work with 9- to 10-year-olds or 15- to 17-year-olds, it is primarily middle-grades youth that I am speaking and thinking of when I talk about the context of my youth care work. However, my practices in working with youth are heavily informed by my other spaces of care and teaching. I have found that the fundamentally queercrip, non-traditional community, and the in-home practices of caregiving in which I participate, are also significant influences on how I approach caring for youth in my practice. Further, a critical piece of how I approach practice is the experience I gained theorizing and practising student-constructed education as an undergraduate student in an emergent, preservice pathway program titled Family and Community Engaged

\footnotetext{
${ }^{5}$ The mainstream concept of what "healing" is, and requires, is also rooted in deeply held ableist ideals of cure and able-bodyness being the goals (Clare, 2017; Piepzna-Samarasinha, 2018). This piece of writing is also an exploration of what an experience of finding healing and wholeness, absent an interest in being unscarred and ablebodied/neurotypical, can look like.

${ }^{6}$ This is a position also recognized in ethnic studies, abolitionist teaching, and civil rights era community freedom schools (to name a few).
} 
Teaching $^{7}$ (FACET). Through this program, I also gained significant experience doing research and curriculum development. A constant across all of these spaces that has made practising from a queercrip paradigm possible is that they are aligned with the resistance of the eliminatory logics reproduced in schooling and state-sanctioned care practices. Our after-school program exists to resist the punitive and punishing nature of K-12 schooling. My role as a caregiver is rooted in disabled community practices and unrecognized by the narrow, punitive, understandings of care held by the state. FACET has grown into a powerful relational space that has faculty and students working together to not only critique and reveal the harm in current and historical practices of schooling, but to build practices of education in our classrooms and lives that counter them.

When I speak of my youth care practice throughout this article, it is certainly in conversation with institutional understandings of youth care and youth work, but I locate my use of the term "youth care" within a more relational, embodied space that explores the many different ways we can build lives and worlds dedicated to caring for youth. The words "child and youth care", aside from designating a field of work, have always felt to me to be, above all, a promise and a goal. There is some weight in that declaration. Part of what comes up in my meditation on why I use the term "promise" is that care as practised in institutional care facilities has done so much harm and perhaps has yet to truly learn what it might mean to adopt a politic of caring for each other in our full humanities. There is a poem I have read over, and over, and over, and over, and over again with each part of myself, in so many places and times in my life. It hits the heart of the emotions that come up for me in contemplating what we have yet to be able to give our youth when we promise them care and safety. It is a poem I hold tenderly at the centre of everything swirling around me day in and day out, at the centre of any future worth building. These lines from "love letter to the babies/they are all ours" (brown, 2012) are my foundation for a queercrip youth care:

everyday the world reminds me that i cannot protect you. i don't know if protecting children has been possible yet on this earth. $\mathrm{i}$ just believe that what we do, or allow to possibly be done, to our babies, in this world, at this time - that is the measure of our humanity.

it's quite possible that this is the purpose of our evolution, to reach a point where we do nothing which takes away from childhood, that protecting childhood is how we grow healthy societies. that the safe unfolding of children into adults shapes every aspect of the worlds we build (stanzas 9-10).

It is this that I work for and wonder and dream of. I see my youth care practice first as a site for liberatory educational praxis and, as written in my practice journals, a space that I hope feels like the possibility of home. My practice itself (re)emerges ${ }^{8}$ in the ways that I interact with youths

\footnotetext{
${ }^{7}$ See https://wce.wwu.edu/facet

${ }^{8}$ I use the term "(re)emerges" in recognition of the many practices and paradigms that we who have been socialized in Western culture may consider to be "emerging" but that in fact already exist and are centrally held practices of other cultures (Indigenous cultures, subaltern cultures, non-mainstream ways of life, etc).
} 
and others, the functions and contours of the spaces I hold, frequent reflection and adjustment, and my application of both the lessons for practice from an embodied queercrip knowledge and lessons from others. Those lessons come from such sources as abolitionist teaching (Love, 2019), critical pedagogy and its critiques (Cervantes-Soon, 2017; Freire, 2005), Emergent Strategy (brown, 2017), and disability justice (Clare, 2017; Mingus, 2019; Piepzna-Samarasinha, 2018; Sins Invalid, 2017). More than anything else, my youth care practice is deeply personal. It is complexly bound up in the very fundamentals of who I am. As I learn and grow in myself and the values, hopes, dreams, and goals I hold closest to my heart, so too does my practice.

\section{Queercrip Paradigms}

I have found that the understandings at the core of queercrip paradigms resonate deeply with brown's (2017) concept of emergent strategy ${ }^{9}$. It has always appeared to me that, in addition to the many other complex traditions that resonate deeply with the concept, emergent strategy speaks to a profoundly queercrip way of interacting with the world. In fact, brown cites Octavia Butler's (2019) Parable of the Sower, a book many disabled folx have read as a disability justice narrative ${ }^{10}$, as a primary influence in the development of emergent strategy. In her work, brown speaks of emergence as "the connective tissue of all that exists ... critical connections over critical mass, building authentic relationships, listening with all the senses of the body and the mind", and of "the way small actions and connections create complex systems, patterns that become ecosystems and societies" (p. 3). In my explorations of this way of moving through the world within a queercrip context, I've called emergence "constellatory connections" or "crip constellations". I've conceptualized it as being a skill developed out of the ways that being disabled teaches you to see how things can trace and touch other things, connections that are obscured for a lot of people: cold can be intricately linked to pain, sleep can be intricately linked to specific parts of digestive function, the arms and tendrils of trauma in our bodies touch our fascia and our sympathetic nervous system, and music can interrupt and rebuild those connections. I located it in being able to learn and relearn to touch and shape change in the connections - those within our bodies, those between our bodies and the earth, those between our bodies and other people, those between our bodies and understandings of what is not yet culturally legible, those between our bodies and the functions of eliminatory space - all at once, all the time. Those connections become just as real as anything tangible and just as traceable as anything else in space. Sometimes we see connections and complexity a lot more easily than we draw air into our lungs. For me, it is this emergence, these crip constellations, that are the heart of a queercrip way of moving through the world.

\footnotetext{
9"Emergent strategy is how we intentionally change in ways that grow our capacity to embody the just and liberated worlds we long for" (brown, 2017, p. 3).

${ }^{10}$ Piepzna-Samarasinha (2018) observed, “To me, Butler's Parable books are a Black disability justice narrative. Lauren often struggles with her nonnormative mind, but it also gives her Black disabled brilliance.” (p. 135). Piepzna-Samarasinha also noted that further key reading on this idea can be found in Dr. Sami Schalk's book Bodyminds Reimagined: (Dis)ability, Race, and Gender in Black Women's Speculative Fiction.
} 
While there may be parts of this paper that name things that run deep in collective queercrip experience, it is far too eliminatory to expect or desire that one paper and one practitioner (especially a White one) can or should write more than just one thread in a larger tapestry of queercrip experience. I write these paradigms as I have experienced and understood them within my own life and experience, but I am a single star in a vast and interdependent night sky of queercrip constellations. I cannot even tell my own entire and complete truth in this one story; the words here are but a few threads of the story I hold in my bones and tissue, sampled at one set of moments in my life. All I can do is write my part of the conversation.

As I share what I have come to know to be true of the queercrip understandings that shape my practice, I honour the nature of those understandings by recognizing that, at every moment, I am a multitude of constellatory selves and possibilities. I am all at once my suicidal youth, the fierce love I've found in radical education, my capacity for collective joy, my moments of isolation so severe they have left scars, and the futures I spend lifetimes each day dreaming of. I am always understanding histories viscerally, full of awe and fear, disgust and hopelessness, hope and desire. I am all at once everything a bodymind can hold, even as I have learned so little of what it has to teach me. In every possible reach of these experiences, I am never only me. I am connections, heartbeats, and heartbreaks, trying something different that could only become possible together, through touching each other's dreams and curiosities, and finding our own tangled up there too.

In constructing these paragraphs, I rely heavily on Piepzna-Samarasinha's (2018) book, specifically their work around "Crip Emotional Intelligence - skills we use within our cultures and with each other" (p. 69) to build a foundation for queercrip paradigms. When I speak about a queercrip way of moving through the world I am informed by more than just my own experience and practice: I first found the words to connect to myself to larger community, history, and movement in the writings of Eli Clare (2017), Alison Kafer (2013), Leah Lakshmi PiepznaSamarasinha (2018), and Mia Mingus (2019). It was in their words that I first felt less utterly alone in the world. It was in their words that I felt human and possible. Everything I ever write and any work I ever do will be in debt to them.

\section{Unconventional Creativity and Determination}

In my third year of undergraduate studies, from May 2019 to March 2020, I wrote and taught a one-time group independent study course ${ }^{11}$ for FACET, the pathway program I mentioned in my practitioner context. In my experience, FACET fundamentally serves as a space for connection, community, study, and research for a number of educators, from faculty to undergraduate students to community members and local K-12 staff. My course, entitled "Imagining Futures for Family and Community Engaged Teaching", was a deep dive into queer and disabled anarchist/abolitionist theory and practice that supported future educators in theorizing on the nature of teaching practices and education. It also facilitated the creation of a collaborative online document that detailed the

\footnotetext{
${ }^{11}$ At the institution I attended, a "group independent study course" is bureaucratically distinct from a standard course - it does not require any sort of formal curriculum review and has no distinct course number.
} 
"core values" of our practices as a FACET community. The core values established by students in this course were informed by our experiences working with youth in the community, queercrip theory, and our experiences with eliminatory spaces in education, such as being made to feel profoundly alone, out of place, and out of touch within the assertions of the curriculum and classroom community. The core values established through the class were: love, vulnerability (with boundaries), affirmative criticality, solidarity, reciprocity, and relationality.

One space from this class that lives bright in my heart and is a powerful example of the creativity, unconventionality, and determination of a queercrip practice took place the Friday before we were moved online because of COVID-19. I hadn't held class the week before due to most of us attending a conference, and - as we only met once a week — it felt imperative that we be together. As someone used to dealing with the pushes and pulls of chronic illness, it was unsurprising to me when I woke up that morning and realized that there was no chance it would be a good enough pain day ${ }^{12}$ to make it to campus.

For a moment I felt my heart drop and the rest of the quarter slip away - the first class I was teaching for higher education suddenly seemed too close to ending abruptly. But then I took a chance. I thought, hey, if writing from bed is a time-honoured disabled way of being an activist and a cultural worker (Piepzna-Samarasinha, 2018), why not teaching from bed too? I'm no stranger to the "that's-scary-because-it's-weird-and-unconventional" look you get when you have to come up with highly inventive solutions to get around the barriers to daily life. I'd gotten that look plenty of times around the university, but I hoped that maybe we had truly built something different enough in this class that what I was envisioning might be possible. I messaged my class and let them know what was going on. I asked them to vote: (a) we do class online, (b) we don't meet this week, or (c) we have class in my tiny apartment and I teach from bed. They unanimously chose the last option and my heart soared. So that day at 1 p.m., I had a room full of my peers probably in the most unconventional education space of their college experience - drinking apple cider, eating snacks, and studying schooling in the United States.

Those few hours broke down the longstanding narrative that I could never teach or succeed in academia as a disabled person. It was, as my sister so marvellously put it in a text to me the other night, "disabled queer heaven". The class brought to life the disability justice spaces that I had been reading and teaching about for years. Rather than just imagining a FACET model for education that was radical, powerful, inclusive, and liberatory, this class brought it into the world. Every day I hold on to that in my writing and teaching. It fuels my dreams of what could be possible for education.

\footnotetext{
12“Pain day" is a term that refers to the level of pain someone with chronic pain is experiencing on any given day. For me, on a "good enough pain day", the level of pain is conducive to getting to campus; on a "bad pain day" caring for my chronic pain becomes the primary goal of that day.
} 
It also speaks to the ways in which we can't just stop being disabled or queer or trans or neurodivergent. Not for things that are only accessible to abled bodyminds, nor just long enough to finish a project, nor to be a more palatable queer, nor because the abled/cis people around us are tired of it. Frequently, when we continue to be disabled and trans in a way that makes people uncomfortable and spaces continue to be inaccessible, eliminatory logic in action throws us away or leaves us behind. It assumes we would be better off dead than living miserably in a society that refuses to actually work towards a future with us in it, and hopes it never has to see us again which is offensive nonsense. Not only because there is no space in a normative imagination to consider that our bodyminds might not inherently make us miserable, but also because we are the ones waking up the next morning despite how much work has been put into structures that, by not making room for our lives, might as well wish us dead. We are the ones who have been shut out and turned away and ignored. Despite how much some people may wish that this exclusion would make us just disappear, we are still here and we have to figure out how the hell to survive.

This isn't new. For centuries, trans and disabled people have been creating ways to survive and build community. We have histories to look back on, once you look hard enough to find them. It does mean that, if we survive, we are often skilled at figuring things out and figuring out how to do that over and over again. Things will change unpredictably: your day will probably never go as planned. I recall running late to a conference, throwing up all over myself on the freeway, driving around a big unfamiliar city trying to find a laundromat and clean clothes, wiping puke off my belt and chest binder with an industrial-sized wet wipe - and still somehow presenting that day. This is a knowledge that runs deep, of how navigating the world is constantly exhausting, of how you will go on a field trip with the youth in your care and find the elevators are broken. Or, you must figure out how to convince five 11-year-olds to help you find the one elevator hidden on the other side of the building so you can access the field trip space. Some days it is wondering how on earth abled people have the energy to balk every time an unconventional solution is proposed. Unconventional solutions save my life weekly and I do not know if there will ever come a point when I don't get that look just about every time I propose one. It is knowing that our lives sometimes depend on our creativity and "the understanding that we are in a constant dance of negotiating how to work while disabled or sick or in pain" (Piepzna-Samarasinha, 2018, p. 71).

Sometimes that determined, unconventional creativity is needed for finding ways to rest, for always (re)discovering not just the ways to scrape by, but the ways to fill our homes (whether that means our beds or our bodyminds or our cars) with practices that hold us how we deserve to be held. Sometimes the determination in unconventional creativity is just the will to walk away without shame or guilt and find better ways to take care of yourself when you try to meet up with your co-workers and find they are on the second floor of a restaurant with no elevator. It is born of learning how to hold heaps of contradictions and how sometimes your oldest understanding of "home" is an in-between: a home found somewhere between this world and the one where we are free. 
International Journal of Child, Youth and Family Studies (2021) 12(3/4): 129-151

\section{Dreaming}

I used to call the ways that our unconventional creativity and determination helped us survive "survival dreaming". I wrote in my journals that survival dreaming is making it to tomorrow by any means possible, knowing the only means that are possible are those that you built out of dreams. Those dreams are often ones that you, and everyone around you, thought impossible yesterday or a few hours ago. Survival dreaming is a dreaming that comes from intimately knowing being left behind. Desperate, hysterical, alone, and incapable of getting to the other side of whatever barrier everyone else seems to walk through like ghosts. Survival dreaming is when you are there and you take a breath, however impossible it feels, and find whatever shreds of possibility imagination can fish out of the currents of fear and conventionality and elimination that swirl ever higher. It gets you to tomorrow, exhausted and in pieces. I owe it everything, but it isn't enough.

I do not often speak of this application of unconventional creativity as dreaming any more; I refrain from doing so mostly in a stubborn acknowledgment that we need another kind of dreaming too. One that heals, cares, and holds. One that abolishes the barriers instead of just desperately finding ways to survive them. A dreaming that builds power in our constellations and is committed to our joy. For me and for so many other queercrip folx, our dreaming is political. We survive in spaces that want us dead, then we dream and build spaces where we can not only live but celebrate our lives. Our dreaming is the creation of everything that should already exist for us, starting from where we find ourselves and with whom we find ourselves. Clare (2017) speaks to this dreaming as "building anew" to make our bodyminds home — an acknowledgment that maybe there is "no return, no restoration, no cure, but rather acceptance, resistance, building anew amidst this dense thicket" (p. 166).

It was in this practice of learning to connect and build anew that I first began to understand the ways that the liminality of this queercrip bodymind has grown the skill to dream futures and build possible lives from those dreams. After surviving a suicide attempt at age 16, I had to learn how to exist in this world and in myself again, in any and all ways I could possibly imagine to: my greatest feat of survival dreaming. I like to think I have been a dreamer as long as I have been alive; whether that was out of necessity or nature I don't know, probably both. I remember vividly during my recovery in my late teens that I could not see a path or place for myself through any means that were expected or offered. I had more grief than I knew what to do with from the years and years and years of forcing myself into a shape that never fit, or was even for me. My greatest grief came not from the trauma of that act in and of itself, but from the realization that as long as I had been alive, I had never held a shape that was my own.

It was from there that I began to live and build and create my dreams of who I would be in a different world. And then I began dreaming of building that world, and hoping for all the futures that would come with it. I started out of spite and rage, refusal and bitterness. I was going to cost the world what it had cost me. As I grew, I began building those dreams deeper, out of joy and love, hope and possibility. I found others doing the same. I found histories I never knew existed. I 
found writing on queerness and disability. I found theory that helped me understand the functions of eliminatory logics that I had not previously had words to name, and how those logics impacted others with different identities from my own. And I found people asking how we could get free together.

When I think about how this works in practice, I think about Fridays on the lawn. On Friday at the afterschool program I work at, I have been tasked with being one of the adults on the courts at the back of the school. I take a big blanket out to the grass on the far edge of the courts and sit in the sun. It has become natural that a group of youth, typically almost entirely queer or trans, will join me. We spend the hour and a half of our program doing our own arts and crafts projects, listening to music, telling stories, and sharing our experiences navigating the world as trans and queer folx. I have the great joy in these spaces of getting to bear witness to these youth growing up and to see them for all of who they are. That alone is something that hardly exists in education or institutional youth care spaces, which bear the legacy of foundations that uphold the restriction of youth agency (Vachon, 2020, p. 67). Especially for students who occupy the margins in multiple ways, there is an experience of never getting to be quite seen, of always carrying around parts of who you are that adults and other youth can't really see or understand or don't have the capacity and knowledge and ability to bear witness to.

Getting to co-create spaces with youth is one of the greatest joys I have ever known. They choose the music and the activities and the conversation, and we are people together. I get to share my knowledge of being queercrip and celebrate with them the ways in which they shape and change and complicate and find home in those knowings as they grow and change and move through different identities and ways of engaging with life. We construct conditions where we can connect across the time and space of our experience to make sense together of how we can navigate the eliminatory logics of religion and heteropatriarchical family structure as different generations of queer people. In the seemingly simple act of constructing space that operates from a queer knowing of the world, we construct a fundamentally different foundation for youth care than the one we had left - the one we would return to when the time came to dissolve our shared space. We modelled for ourselves, and hopefully for all those we will ever be in constellation with, a different possibility for a future where all our spaces are built from the joy of knowing each other in all our queer(crip)ness.

This dreaming that builds lives for us is known also as "prefigurative politics" — "a fancy term for the idea of imagining and building the world we want to see now" (Piepzna-Samarasinha, 2018, p. 149), which implies "living and relating differently with others here and now" (Bergman \& Montgomery, 2018, p. 38). One of the questions I get asked most frequently in talking about my work is how I balance future dreaming with tangible action day-to-day. My answer is always that, for me, they are the same. An extraordinary thing about crip culture is that it is always here and there, it is always grounded in the realities of what our bodyminds need urgently and the yet-to-be of our wildest imaginations that wonder fascinatedly about what could be possible. Action fuelled by dreams. In my youth care, it is both imagining a radical education praxis built from the ground 
up as I fall asleep as well as waking up the next day to lean into all the little constellation-sparking connections throughout a day that continue to make those imaginings feel possible. Sometimes, that means affirming the joy a youth shares with me about their queer identity, or putting on eyeliner and knowing myself in the mirror. Other times, it is meeting with parents and other educators to brainstorm abolitionist strategies for community organizing. From time to time, it is spending an extra 3 hours lingering in a friend's car talking about the intricacies of colonialism, or noticing how a fern almost seems to smile at the sky. It grows and builds, becomes a dozen things, and those constellations become the foundation for programs, practice, and community that ensure I am never dreaming a future in isolation.

\title{
Constellatory Complexity
}

\author{
And we have had to learn \\ To hold complexity \\ Like it is stardust \\ Shimmering, shifting \\ Between our fingertips \\ Known intimately by its indescribability
}

-from my practice journals

When I don't wear a chest binder, some people assume that I am somehow no longer trans. I don't walk around with a sign letting them know if I'm not wearing the binder due to pain, having trouble breathing, being too exhausted to wrestle into it, or just because I am comfortable not wearing it that day - and they don't ask (not that they are entitled to that knowledge). Their assumption isn't only that my gender identity is tied to my chest (it is not), but that my use of he/him pronouns signals male/masculine and should thus signal a cis/binary ideal presentation (neither of which I identify with or strive for). That is the cisnormativity of it all. And it is not only violent in its cisnormativity, but in the fact that cisnormativity is also inherently ableist because it ties gender normativity to an able bodymind, one that can perform gender to cisnormative specifications, which my bodymind cannot — and could not even if I wanted it to (again, I do not). Both of those logics capture and constrain the complexity of trans and disabled experiences and eliminate the histories and knowledges of those experiences in their attempt to wrestle our bodyminds into a particular kind of embodiment - a single truth, a single narrative. This analysis of eliminatory forces also prompts us to ask how norms about health, body, and gender are also based in colonial ideas of gender, on White bodies and minds, and on access to capital. The assumptions of eliminatory spaces all, always, function to lift up a particular kind of bodymind experience and eliminate all others. As a result, normative imagination does not have the capacity to comprehend queercrip stories.

Queercrip embodiment comes with a baseline understanding of a multiplicity of self and relationships that can never be simplified. This speaks to our crip constellations - to the ways we 
have come to understand, in tracing tangled strands of existence and contradiction, that the universe is multifaceted enough to hold us in our full humanity. Having to learn to experience life in indescribably complex constellations and connections is a queercrip skill that can also be applied to our spaces and practices. This can arise through making room for the reality that even tiny functions of space are intricately connected to eliminatory logics and to understanding how a classroom setup can be an eliminatory legacy of colonialism entangled with ableism and antiBlackness. It is knowing that there is always more than what is seen and more than what can be communicated in a moment (or a lifetime), and having it take precedence in our interactions with youth and each other. It is an understanding that we cannot simplify our looping and contradicting histories any more than we can leave each other behind, because that is what eliminatory spaces have done to us more times than we can count. It doesn't mean that we see everything or know everything: it means that we know intimately we are far from being able to see or know everything. We will know more intimately the complexity of those connections that we experience most presently, and we will have to listen to and trust how others see and experience their own constellations. It is a lifelong commitment to practising complexity. It is walking through life knowing better than to assume. Piepzna-Samarasinha (2018) explained:

It's always asking: if you can touch, what you call your body or your sick, what you need, if you even want suggestions for your issue or if you just want listening. It's understanding that each disabled person is the expert on their own body/mind. (p. 70)

\section{Care}

Queercrip care makes home in our relationships to each other. Our practices of care are deep, winding, creative, complex, and contradictory. They also, perhaps fundamentally, are relationships built and sustained mutually. With the youth I work with, as well as the friends and family I have learned how to care with, this most often shows up as a co-construction and co-determination of how best to meet all the needs present in the room - both in that moment and as long-term practices. It has been a somewhat experimental process of listening to each other's experiences and trying our best to name and determine the needs that we have which have not yet been met in those experiences - and then trying whatever solutions we can dream up. This process is responsive: it involves listening and asking. For example, it may mean noticing that a particular youth seems reluctant to engage in big groups and always has their headphones on, but rather than assuming that they are simply unengaged for the sake of being unengaged, asking if they need a quieter space, or if there is something in that environment that feels "too much". It is also knowing that you will not always get an answer - because trusting people with your needs and care is to make yourself vulnerable, or because a response is not easily accessible — and respecting that while continuing to ask questions and offer different options for care. It will be trial and error in each situation, recognizing that each relationship is unique, and learning the practices that work best within its dynamic — what worked and what did not being determined by those receiving care. 
A queercrip understanding of care is built on a desire and necessity to build away from intimately known histories of the violent and carceral state systems that have taken on the guise of care (Piepzna-Samarasinha, 2018, pp. 38-39). This aim, to build beyond eliminatory care practices, speaks directly to the field of child and youth care, which has come to exist within the same patriarchal, colonialist, and curative (ableist) context of care that queercrip paradigms identify and resist: one that frames care as "a practice of intervening, categorizing, saving, containing, fixing, and purifying" (Vachon, 2020, p. 72). Queercrip care resists the assumption that a bodymind defined by eliminatory logics as correct and healthy (abled) is the only desirable bodymind. It resists an idea of cure based on that assumption and the resulting justification of becoming more abled "by any means necessary". Queercrip care recognizes the inherent value, worth, desirability, and agency of people just as we are, in the bodyminds we are currently in. We all need care, in some capacity or another, and we all have the right to be the one directing and determining that care.

Caring for queercrip humanity is not assuming. Caring for queercrip futures is committing to a practice of dreaming — right now and with all the time we have left. Finding the unconventional solutions that refuse to leave anyone behind is an act of care. Dismantling harmful and exploitative systems and practices is care. Care is unlearning the practices that hurt each other and ourselves. Care is accountability to that practice and each other (Mingus, 2019).

\section{Recommendations for Child and Youth Care}

For child and youth care practitioners, the first place I recommend examining is the imaginaries of your practice. What are you building for and towards? Not just what do you believe is possible, but what possibilities does your practice communicate to youth, families, and your community? What logics do your imaginaries develop from? How do those logics define the boundaries of a space, and how might other logics explode those borders? Does the imagination your practice rests upon allow you and the youth you work with to "imagine ourselves and others otherwise" (Butler, 2004, p. 29)? Or does it rest in the assumption that eliminatory logics are simply what is and will continue to be?

Even if you have never had to dream in order to survive, you can act in the service of building the dreams of those who do. Build your practice by centring the dreams of Black, Brown, Indigenous, queer, disabled, migrant, immigrant, Muslim, houseless, and low socioeconomic status youth. Don't assume what their dreams are or believe yourself entitled to them; instead, listen to them when they are offered. Facilitate dreaming in your spaces and listen to their constellations, and not just the conventional parts, but also the parts you want to dismiss. Participate in action that works to dismantle the systemic barriers to those dreams, whatever that looks like for your particular context. Action could be on a bigger scale in your community, through interpersonal relationships, or in how you are structuring your space; it likely will be all 
of those in whatever ways are most powerful in your context. Grow your imaginaries through building collective and meaningful connection to the community in your youth care context.

Work to lean into a practice of constellations. Hold as much complexity and messiness and contradiction and multiplicity and curiosity as you possibly can, and then - once you've gotten the hang of that much - even more. It is always going to be much harder than falling back into simple narratives, but it is also needed more than you can imagine. And as the foundation of it all, rest your every practice in the care of nurturing love, joy, wholeness, humanity, and dreams for yourself, your youth, and your community - because no other work becomes possible or sustainable without that.

\section{Working Towards Liberatory Child and Youth Care}

In late 2019, I began building a critical photography practice with youth, facilitating a photography club during our hour of programming time on Monday nights. This was one of the first projects that I built alongside youth from the ground up. The creation of the space was informed and supported by my mentors and my co-workers, asked for and envisioned and constructed by students, and realized through inspirations, conversations, passions, and relationships. The very growth of this space came to exist out of constellations. The project has been a site and space for students to explore and reclaim their connection to a building, land, and self that is otherwise defined during the school day primarily through eliminatory logics. The practice of creating and taking pictures is one of joy and creativity that can function as a way for students to theorize about their world and tell their stories.

In facilitating this project, I wanted students to direct the club, choosing, for instance, what photos they wanted to take and where we would wander on campus to take them. I did this partially in reaction to noticing that our school building has a large, metal, slotted gate that is closed during non-instructional hours and divides the classrooms from the common areas, such as the gym and the lunchroom. There are several ways to travel between the two spaces when the gate is down, but all of them require a staff key for access. Extracurricular activities are typically held in the common areas of the school and separated from the classrooms by the gate. Not only is this architecture plainly carceral in nature, but it meant that students were physically cut off from building extracurricular (non-eliminatory) connections to their classroom space.

Over the year that I supported this club, students most frequently elected to have photoshoots in the instructional wing of the building and outside - places where they typically would have been unable to simply hang out. What I saw when students were able to choose to explore their extracurricular relationships with those parts of the building was that the images they chose to create grew from reflections on how parts of those spaces felt to them (such as taking pictures of each other reaching through the gate into the other section of the building with expressions that conveyed grief and longing) to a reclamation of the school campus as their own (such as artistically 
posed group photos, the creative use of stuffed animals as models in all sorts of silly and brilliant ways, and the inclusion of pride flags in self-portraits).

In writing this paper, it has become clear to me how queercrip knowledge — such as never leaving anyone behind, caring for many different interests and needs, and telling more complex stories than words could alone - was shared through this photography project. The youth and I learned and practised how to build a community that moved through our space and time together. We practised coming up with ways to meet all of our needs. Sometimes we waited a few more minutes in one spot for the last photographer to finish up their shot. We took the elevator instead of the stairs or split into two groups if we had students who were claustrophobic. We balanced our time outside with the needs of those most sensitive to cold and balanced our time inside with consideration for those who were easily overstimulated. We imagined new projects and planned field trips. We talked about how certain rooms, hallways, portables, patches of grass, and fences made us feel and why; what memories they brought up and why; how we connected those feelings to bigger patterns in our worlds; and how we could capture any measure of that on film.

I hope that by now it is becoming clear that I do not share my queercrip experiences and my joy in a practice located in those experiences as information to be reabsorbed into the established eliminatory logics that are the foundation of institutional spaces of youth care, of classrooms, and of academia. Nor do I do so with the goal of having those spaces reformed enough that some more privileged queercrip folx can exist in them a little more easily. I share my experiences in order to build understanding that the only way I have been able to survive - and believe in even the possibility of a future where every child is loved in their full humanity — is by constantly working to build and nourish deep constellatory connections that increase the possibilities we can imagine for liberatory futures. In my life, that practice operates from a queercrip paradigm in whatever ways I know to be possible, and is in collaboration and solidarity with thousands of other paradigms working to move beyond eliminatory conceptions of what futures are possible or even worth building. That work is impossible without breaking apart the systemic constructions that, in their basic function, only wish to reproduce power maintained through the exploitation, subjugation, dehumanization, and elimination of those that occupy the margins. If our youth care spaces are to be liberatory, they must be built up from different roots.

\section{Queer Joy as a Tool for Intergenerational Healing}

I note that practices such as these, grounded in subaltern embodiment and demanding justice, are difficult and exhausting. My own has been able to continue to exist because, although the necessity for struggle is not walking away any time soon, my practice is not first and only a relationship defined by its opposition to eliminatory logics: more critically, it relates to lifesustaining practices of healing and joy. It has been extraordinary beyond anything I myself could have imagined as a youth to experience spaces where queer folx of various intersections from ages 11 to 40-plus could share experiences and joy, and build community. Some of the remarkable 
qualities of these spaces are: lack of consumption of queer identity ${ }^{13}$, affirmation, acceptance, resisting shame, access to community roots and histories, and that they are not just for students or for adults but are created together and promote mutual healing.

I have been a part of "love declarations", where students and adults take turns on the microphone speaking their love for each other and the community into the space. I felt those declarations healing parts of me I didn't know were broken or missing. They were more than fire or hope, but made me feel like I had stumbled into another world, one where the kind of care I dream of but sometimes think impossible was, instead, defining our lives. I know the future we dream of is possible because I have seen portals to it in the coming out stories of youth that redefine coming out; in their new iterations of queer identity theorized at age 12; in celebration of that which is messy and undefined; in moments of childhood I never got to experience; and in the passing of knowledge not just from adults to children, but freely across our different experiences in finding wholeness. It is in these moments that I recognize us building homes, not the only way I had ever known - in the in-between, from shared grief, isolation, shame, and unbelonging but in the centre of our lives, from humanity, love, and possibility. I wonder and hope for a generation that never learns the lessons that teach them to build their first home in desolation, for the promise of a childhood that knows first the wonder of the cosmos, and for a world worthy of holding and bearing witness to that brilliance.

Bits and pieces of these spaces are scattered across my everyday working with youth and alongside older queer staff and mentors. This joy is a steadfast foundation for our dreams, our healing, and our futures.

\section{Writing Ourselves Home}

My experience of the world has never quite lined up with those that are visible in most spaces, especially institutional ones, and over time I have come to identify a sort of dissociating of self and body that accompanies my presence in those spaces. Through my time in academia and as a youth care practitioner, my life has come to be about figuring out how to tell the stories of my existence that are too expansive and complex to be comprehended using the logics of those spaces. It has also been learning that these stories must be told, in conversation with the many other stories that complexify and reveal the contradictions of mine, in order to grow our collective capacity to build spaces in youth care and in education that overwhelm the bounds of eliminatory imaginations.

The struggle to write my bodymind and have it find validity has been a constant through my years. The logics of eliminatory spaces are not built to hold a body within their bounds, especially

\footnotetext{
13“"Lack of consumption of queer identity" means that our identities as queer people in the space are not primarily there to be consumed, observed, debated, or fascinated at by others through a cisheteronormative gaze. Rather, to just exist and be present without also being on display.
} 
a queer, disabled one. They render my stories and my experiences illegible. These spaces strive to erase bodies, to focus on disembodied minds, convincing teachers, researchers, students, and youth that any truth that exists does so in absence of feeling and experience. Those of us who cannot be separated from our bodies get lost or, maybe more truthfully, intentionally obscured and pushed out.

When the weight of eliminatory logics crashes down around me and it suddenly becomes breathtakingly painful to hold onto myself, I continue to rediscover the possibility of doing so in how the dreams we wrap ourselves in sometimes touch and we find ourselves a little bit less alone. I rediscover how my bodymind is a text of our stories, the scars and fidgets and curves and contradictions of in-between. I remember that I can breathe stardust and laugh with mischief and weightless joy in the same moments that I stop breathing from the pain. I find I can pull all these skills from my ever-expanding bodymind and build worlds with them. It is within these joys of queercrip experiences and connections that I find the will to write a practice, with every breath and utter abandon, that gives voice to the memories and scars and hopes and desires that dwell in the creases of my body and carry us towards the possibility of home. 
International Journal of Child, Youth and Family Studies (2021) 12(3/4): 129-151

\section{References}

Asch, A. (2005). Recognizing death while affirming life: Can end of life reform uphold a disabled person's interest in continued life? Hastings Center Report, 35(6), S31-S36. doi: $10.1353 /$ hcr. 2005.0088

Ball, M. (2016). Criminology and queer theory: Dangerous bedfellows? Palgrave Macmillan. doi:10.1057/978-1-137-45328-0

Bergman, C., \& Montgomery, N. (2018). Joyful militancy: Building thriving resistance in toxic times. AK Press.

Briggs, L. (2012). Gay and lesbian adoption in the United States. Somebody's children : The politics of transracial and transnational adoption (pp. 241-268). Duke University Press.

brown, a. m. (2012, December 16). Love letter to the babies/they are all ours [blog]. https://adriennemareebrown.net/2012/12/16/love-letter-to-the-babiesthey-are-all-ours/

brown, a. m. (2017). Emergent strategy: Shaping change, changing worlds. AK Press.

brown, a.m. [@adriennemareebrown], \& Reagon, T [@toshireagon]. (2020, June 22). Octavia’s Parables IG Live [Video File]. Retrieved from https://www.instagram.com/tv/CBv zkEB9Oz/

Butler, J. (2004). Undoing gender. Routledge.

Butler, O. E. (2019). Parable of the sower. Headline Book Publishing.

Cervantes-Soon, C. G. (2017). Juárez girls rising: Transformative education in times of dystopia. University of Minnesota Press.

Conrad, R. (2014). Against equality: Queer revolution, not mere inclusion. AK Press.

Clare, E. (2017). Brilliant imperfection: Grappling with cure. Duke University Press.

Crenshaw, K. (1989). Demarginalizing the intersection of race and sex: A Black feminist critique of antidiscrimination doctrine, feminist theory and antiracist politics. University of Chicago Legal Forum, 1989(1), 139-167.

Eastwood, C. (2004). Million Dollar Baby [Film]. Warner Bros.

Freeman, E. (2007). Introduction. GLQ: A Journal of Lesbian and Gay Studies, 13(2-3), 159176. doi:10.1215/10642684-2006-029

Freire, P. (2005). Pedagogy of the oppressed (30th Anniversary ed.). The Continuum International Publishing Group.

Kafer, A. (2013). Feminist, queer, crip. Indiana University Press. 
International Journal of Child, Youth and Family Studies (2021) 12(3/4): 129-151

Leong, N. (2013). Racial capitalism. Harvard Law Review, 126(3), 2151-2226. https://harvardlawreview.org/2013/06/racial-capitalism/

Love, B. L. (2019). We want to do more than survive: Abolitionist teaching and the pursuit of educational freedom. Beacon Press.

Lytle Hernández, K. (2017). Introduction: Conquest and incarceration, In K. Lytle Hernández, City of inmates: conquest, rebellion, and the rise of human caging in Los Angeles, 1771-1965 (pp. 1-15). University of North Carolina Press.

Mingus, M. (2019, December 18). The four parts of accountability: How to give a genuine apology part 1 [Blog]. https://leavingevidence.wordpress.com/2019/12/18/how-to-give-agood-apology-part-1-the-four-parts-of-accountability/

Moraga, C., \& Anzaldúa, G. (Eds.). (1983). This bridge called my back: Writings by radical women of color. Aunt Lute Books.

Muñoz, J. E. (2006). Feeling brown, feeling down: Latina affect, the performativity of race, and the depressive position. Signs: Journal of Women in Culture and Society, 31(3), 675-688. doi: $10.1086 / 499080$

Obergefell v. Hodges, 576 U.S. _ _ (2015). https://www.supremecourt.gov/opinions/14pdf/14556 3204.pdf

Piepzna-Samarasinha, L. L. (2018). Care work: Dreaming disability justice. Arsenal Pulp Press.

Sins Invalid. (2017). Skin, tooth, and bone - The basis of our movement is people: A disability justice primer. Reproductive Health Matters, 25(50), 149-150. doi:10.1080/09688080.2017.1335999

Strauss, D. (2018, February 12). Queer crips: Reclaiming language. Making Queer History. https://www.makingqueerhistory.com/articles/2018/2/11/queer-crips-reclaiming-language

Vachon, W. (2020). Queering child and youth care. International Journal of Child, Youth and Family Studies, 11(2). doi:10.18357/ijcyfs112202019519

Wilchins, R. A. (2007). Queer theory, gender theory: An instant primer. Alyson Books. 